\title{
Abdominal Obesity Is Characterized by Higher Pulse Pressure: Possible Role of Free Triiodothyronine
}

\author{
Giovanni De Pergola, Adele Nardecchia, Alida Ammirati, Domenico Caccavo, \\ Serena Bavaro, and Franco Silvestris
}

Oncology Section, Hypertension Outpatient Center, Clinical Nutrition Outpatient Center, Department of Internal Medicine and Clinical Oncology, School of Medicine, University of Bari, Policlinico, Piazza Giulio Cesare 11, 70124 Bari, Italy

Correspondence should be addressed to Giovanni De Pergola, gdepergola@libero.it

Received 27 July 2012; Accepted 27 August 2012

Academic Editor: Kazuko Masuo

Copyright ( $) 2012$ Giovanni De Pergola et al. This is an open access article distributed under the Creative Commons Attribution License, which permits unrestricted use, distribution, and reproduction in any medium, provided the original work is properly cited.

Objective. This study examined whether obesity is characterized by higher $24 \mathrm{~h}$ mean pulse pressure $(24 \mathrm{~h}$ mean SBP-24 h mean $\mathrm{DBP})$ and whether free thyroid hormones $\left(\mathrm{FT}_{3}\right.$ and $\left.\mathrm{FT}_{4}\right)$ have a relationship with $24 \mathrm{~h}$ mean pulse pressure. Methods. A total of 231 euthyroid overweight and obese patients, 103 women and 128 men, aged 18-68 yrs, normotensive $(n=69)$ or with recently developed hypertension $(n=162)$, never treated with antihypertensive drugs, were investigated. Fasting insulin, $\mathrm{TSH} \mathrm{FT}_{3}, \mathrm{FT}_{4}$, glucose, and lipid serum concentrations were measured. Waist circumference was measured as an indirect parameter of central fat accumulation. Ambulatory blood pressure monitoring (ABPM) was performed. Results. $24 \mathrm{~h}$ mean pulse pressure (PP) showed a significant positive correlation with BMI $(P<0.001)$, waist circumference $(P<0.001)$, and $\mathrm{FT}_{3}(P<0.001)$ and insulin serum levels $(P<0.05)$. When a multivariate analysis was performed, and $24 \mathrm{~h} \mathrm{PP}$ was considered as the dependent variable, and waist circumference, $\mathrm{FT}_{3}$, insulin, male sex, and age as independent parameters, $24 \mathrm{~h}$ mean PP maintained a significant association only with waist circumference $(P<0.001)$ and $\mathrm{FT}_{3}$ levels $(P<0.05)$. Conclusion. Our results suggest that $\mathrm{FT}_{3}$ per se may contribute to higher pulse pressure in obese subjects.

\section{Introduction}

Overweight and obesity are associated with elevated blood pressure, and high percentage of hypertensive patients are overweight and obese [1]. Subjects gaining weight are at higher risk for hypertension $[2,3]$, whereas the weight reduction decreases blood pressure levels as well as the complications related to hypertension [4]. Obesity has also been recognized as an independent risk factor for arterial hypertension [5], and, in particular, the Framingham Heart Study showed that approximately $65 \%$ to $75 \%$ of overweight and obese patients are at risk for hypertension [6]. Examining 3216 outpatient subjects who were never treated with antihypertensive medication, Kotsis et al. showed that confirmed ambulatory blood pressure hypertension was found to be higher in both overweight and obese individuals compared with normal weight subjects [7]. As far as fat distribution is concerned, visceral fat has the most important impact on blood pressure elevation [8].

Concerning the mechanism relating obesity to hypertension, most obese humans have increased sympathetic activity [9], and some authors have shown that sympathetic activation is higher in subjects with central than with peripheral phenotype of obesity $[10,11]$. Moreover, most obese patients have hyperinsulinemia, and it is well known that insulin stimulates sympathetic activity [9] and that this effect occurs even when the insulin levels are included within the physiological range [12]. The renin-angiotensin-aldosterone system (RAS) has also been identified as an additional abnormality that can explain the association between obesity and hypertension [13-15]. Lastly, it has been shown that blood pressure and obesity covariation are mediated by circulating high levels of leptin, suggesting that the body fat has 
only a weak independent effect on blood pressure variation after adjustment for leptin levels [16].

It has been also shown that hyperinsulinemia is determinant for unfavourable metabolic aspects of metabolic syndrome, whereas catecholamines seem to be important for the development of impaired glucose metabolism and hypertension [17].

A recent study performed in a cohort of overweight and obese patients, never treated by antihypertensive treatment, showed that obesity is associated to the tendency to higher systolic blood pressure and lower diastolic blood pressure, at least before that hypertension becomes stable, corresponding to profound alterations in artery structural and functional characteristics [18]. The same study has shown that daily noradrenaline production contributes to higher $24 \mathrm{~h}$ mean systolic blood pressure levels [18]. These results seem to suggest that obesity per se is associated to higher pulse pressure, that is, the difference between systolic and diastolic blood pressure.

Interestingly, $\mathrm{FT}_{3}$ serum levels are higher in women with abdominal obesity and are independently associated with waist circumference [17]. Noteworthy, systolic blood pressure is typically elevated, and diastolic pressure is often low in patients of thyrotoxicosis, which results in a higher pulse pressure, and these findings are attributable to increased cardiac output, stroke volume, heart rate, and cardiac contractility and a marked fall in systemic vascular resistance [19]. By contrast, hypothyroidism causes opposite changes [19]. Therefore, it may well be that patients with abdominal obesity having higher $\mathrm{FT}_{3}$ serum levels have also higher pulse pressure. However, at the best of our knowledge, no study has investigated a possible significant relationship between free thyroid hormones and blood pressure levels in obesity. The present study was thus designed to address this specific question. In particular, we examined whether $\mathrm{TSH}, \mathrm{FT}_{3}$, and $\mathrm{FT}_{4}$ serum levels may predict $24 \mathrm{~h}$ mean systolic and diastolic blood pressure levels and pulse pressure in a cohort of 231 euthyroid overweight and obese patients, aged 18-68 yrs, who had never received antihypertensive medication, independently of other parameters.

\section{Methods}

2.1. Subject Population. The patients were consecutively enrolled at the Outpatient Clinic for the Study of Hypertension, Department of Internal Medicine and Clinical Oncology, University of Bari, School of Medicine. Concerning the inclusion criteria, they were recruited at the first medical examination in the absence of antihypertensive drugs. In addition, they showed a BMI higher than 25.0. All of them were addressed to the Outpatient Clinic by their general practitioners because of a recent increase of their ambulatory blood pressure levels.

To obtain the selected population for this study, patients with the following disorders were excluded: endocrinological diseases, diabetes mellitus, stroke, transient ischemic attack, angina pectoris, heart infarction, claudicatio intermittens, congenital heart disease, or ECG abnormalities. Smokers and patients with impaired $\mathrm{FT}_{3}$ and $\mathrm{FT}_{4}$ levels were also excluded.

Thus, the study enrolled 231 patients, including 103 women and 128 men, aged 18-68 yrs. The trial protocol has been approved by an ethical committee and meets the standards of the Declaration of Helsinki in its revised version of 1975 and its amendments of 1983, 1989, and 1996.

All patients reported to have normal fasting blood glucose levels before enrolment into the study, but 7 had a fasting blood glucose $\geq 126 \mathrm{mg} / \mathrm{dL}$, but lower than $140 \mathrm{mg} / \mathrm{dL}$.

All study subjects were judged in good health on the basis of physical examination, medical history, routine blood work, urinalysis, and electrocardiogram. None of patients were receiving any medication (including oral contraceptives for premenopausal women and hormone replacement therapy for postmenopausal women) since at least three months before the enrollment into the study. Moreover, none of them had been involved into intensive or competitive physical activity prior to the enrollment. During the testing period, all subjects were asked to keep their normal mixed diet and not to perform any sporting activity. The day before the measurement, they were abstained from both caffeinated and alcoholic drinks but maintained their normal diet.

2.1.1. Anthropometric Measurements and General Data. Body weight was measured to the nearest $\mathrm{kg}$. Height was determined to the nearest $\mathrm{cm}$. BMI was calculated as the weight $(\mathrm{kg})$ divided by the square of height $(\mathrm{m})$. Waist circumference was measured at the narrowest part of the abdomen, that is, at the natural indentation between the 10th rib and the iliac crest (minimum waist).

2.1.2. Blood Pressure Measurements. Outpatient Clinic blood pressure was recorded on at least three different occasions, using a mercury manometer with an appropriate cuff size. Ambulatory blood pressure was measured with 15-minute intervals from 07:00 to 23:00 and with 30-minute intervals from 23:00 to $07: 00$ for consecutive $24 \mathrm{~h}$, starting from 08:30 (Ultralite ABPM Monitor 90217, SpaceLabs Media Inc, Redmond, WA). Heart rate was measured over $24 \mathrm{hrs}$ by the same instrument. All ABPM measurements were valid, meaning that $<30 \%$ of the measurements were missing, data were lacking for an interval of $<2 \mathrm{~h}$, and the nighttime sleep period was never $<6 \mathrm{~h}$ or $>12 \mathrm{~h}$.

According to the 2007 ESH-ESC Practice Guidelines for the Management of Arterial Hypertension [20], hypertension was confirmed when $24 \mathrm{~h}$ mean systolic blood pressure was $\geq 125 \mathrm{mmHg}$ and/or $24 \mathrm{~h}$ mean diastolic blood pressure was $\geq 80 \mathrm{mmHg}$. Thus, 162 subjects were affected by hypertension, whereas 69 individuals were normotensive. Pulse pressure was formally defined as the daily mean systolic pressure minus the daily mean diastolic pressure.

2.1.3. Hormone and Metabolic Parameters. Blood samples were drawn between 08:00 $\mathrm{h}$ and 09:00 h after an overnight fast, within one week from the day of the ambulatory blood pressure measurement. Serum insulin concentrations were measured by radioimmunoassay (Behring, Scoppitto, Italy), 
and intra- and interassay coefficients of variation were $3.7 \%$ and $7.5 \%$, respectively. Serum $\mathrm{TSH}, \mathrm{FT}_{3}$, and $\mathrm{FT}_{4}$ serum levels were measured as previously described [21]. Plasma glucose levels were determined by the glucose-oxidase method (Sclavo, Siena, Italy), and plasma lipids (triglycerides, total cholesterol, and HDL cholesterol) were measured by an automatic colorimetric method (Hitachi; Boehringer Mannheim, Mannheim, Germany).

Insulin resistance was assessed by using the homeostasis model assessment $\left(\mathrm{HOMA}_{\mathrm{IR}}\right)$ [22].

2.2. Statistics. Results were calculated as mean and standard deviation (sd) for all parameters. Significant relationships between $24 \mathrm{~h}$ mean SBP, $24 \mathrm{~h}$ mean DBP, and $24 \mathrm{~h}$ mean PP and all other parameters were evaluated by Pearson's correlation coefficient. A multiple regression analysis was performed to test the joint effect of different variables on $24 \mathrm{~h}$ mean SBP or $24 \mathrm{~h}$ mean DBP or $24 \mathrm{~h}$ mean PP. $P$ values of $<0.05$ were considered statistically significant. Statistical power was analysed using STATISTICA Power Analysis (StatSoft Inc., Tulsa, Oklahoma), and the statistical analyses were made using STATISTICA 6.1 software (StatSoft Inc., Tulsa, Oklahoma).

\section{Results}

Table 1 shows general and anthropometric parameters, ABPM data, and metabolic and hormone variables in overweight and obese subjects under study.

Table 2 shows the relationship between $24 \mathrm{~h}$ mean systolic (SBP) and $24 \mathrm{~h}$ mean diastolic blood pressure (DBP) with all other parameters. SBP showed a direct significant association only with waist circumference and $\mathrm{FT}_{3}$ levels, whereas DBP showed a significant relationship only with age (positive) and BMI (negative).

Table 3 shows the results of a linear multivariate analysis, with $24 \mathrm{~h} \mathrm{SBP}$ considered as the dependent variable and $\mathrm{FT}_{3}$ levels, male sex, and age as independent parameters (adjusted $\left.R^{2}=0.054, P<0.001\right) . \mathrm{FT}_{3}$ levels, male sex, and age showed an independent significant association with $24 \mathrm{~h} \mathrm{SBP}$; however, when waist circumference was also entered into the analysis (adjusted $R^{2}=0.071, P<0.001$ ), only age and waist circumference maintained an independent association with $24 \mathrm{~h}$ systolic blood pressure (Table 4 ).

Table 5 shows the relationship between $24 \mathrm{~h}$ pulse pressure (PP) with all other parameters. $24 \mathrm{~h}$ PP showed a significant positive association with BMI, waist circumference, insulin and $\mathrm{FT}_{3}$ levels.

Table 6 shows the results of a linear multivariate analysis, with $24 \mathrm{~h}$ PP considered as the dependent variable and male sex, age, and insulin and $\mathrm{FT}_{3}$ levels as independent parameters (adjusted $R^{2}=0.137, P<0.001$ ). Only $\mathrm{FT}_{3}$ levels and waist circumference maintained an independent significant association with $24 \mathrm{~h}$ PP. Again, when $\mathrm{HOMA}_{\mathrm{IR}}$ was introduced in the multivariate analysis in substitution of insulin, only $\mathrm{FT}_{3}$ levels and waist circumference maintained an independent significant association with $24 \mathrm{~h}$ PP (data not shown).
TABLE 1: General and anthropometric parameters, ABPM data, and metabolic and hormone variables in subjects under study $(n=$ 231).

\begin{tabular}{lc}
\hline Age $(\mathrm{yrs})$ & $42.6 \pm 10.8$ \\
Body mass index $\left(\mathrm{kg} \cdot \mathrm{m}^{-2}\right)$ & $34.2 \pm 6.8$ \\
Waist circumference $(\mathrm{cm})$ & $111.3 \pm 14.5$ \\
Systolic blood pressure $(\mathrm{mmHg})$ & $132.9 \pm 8.6$ \\
Diastolic blood pressure $(\mathrm{mmHg})$ & $83.2 \pm 7.0$ \\
Heart rate $($ beats per minute $)$ & $78.4 \pm 8.5$ \\
Fasting blood glucose $(\mathrm{mg} / \mathrm{dL})$ & $94.9 \pm 13.2$ \\
Fasting insulin $(\mu \mathrm{UI} / \mathrm{mL})$ & $32.0 \pm 21.9$ \\
HOMA $\mathrm{IR}$ & $7.67 \pm 5.97$ \\
Triglycerides $(\mathrm{mg} / \mathrm{mL})$ & $125.5 \pm 64.5$ \\
$\mathrm{HDL}_{\mathrm{i}}$ cholesterol $(\mathrm{mg} / \mathrm{mL})$ & $43.1 \pm 11.7$ \\
Total cholesterol $(\mathrm{mg} / \mathrm{mL})$ & $198.1 \pm 44.2$ \\
$\mathrm{TSH}(\mu \mathrm{UI} / \mathrm{mL})$ & $1.72 \pm 0.94$ \\
$\mathrm{FT}_{3}(\mathrm{pg} / \mathrm{mL})$ & $3.25 \pm 0.42$ \\
$\mathrm{FT}_{4}(\mathrm{pg} / \mathrm{mL})$ & $10.8 \pm 1.40$ \\
\hline
\end{tabular}

\section{Discussion}

At the best of our knowledge, this is the first study examining the relationship between free thyroid hormones and $24 \mathrm{~h}$ mean blood pressure levels in euthyroid overweight and obese subjects, who had never received antihypertensive medication.

On the basis of a direct independent relationship between daily mean pulse pressure and waist circumference, this study shows that abdominal obesity is characterized by higher pulse pressure, at least before artery remodeling and hypertension stabilization, thus confirming the results of a recent study performed by our group [18].

The strongest novel finding of this study was the direct relationship between $\mathrm{FT}_{3}$ levels and pulse pressure, independently of age, sex, insulin levels, and $\mathrm{HOMA}_{\mathrm{IR}}$. These results support the hypothesis that higher $\mathrm{FT}_{3}$ circulating levels per se may be responsible for an increase in systolic blood pressure and a decrease of diastolic blood pressure in subjects with abdominal obesity. The relationship between insulin levels (or $\mathrm{HOMA}_{\mathrm{IR}}$ ) and pulse pressure was not maintained when $\mathrm{FT}_{3}$ levels were introduced in the multiple regression analysis, thus apparently excluding that insulin or insulin resistance has a significant role in the association between pulse pressure and abdominal obesity or between pulse pressure and $\mathrm{FT}_{3}$ levels.

We found also a direct relationship between $\mathrm{FT}_{3}$ levels and daily mean SBP, independently of age and sex.

All these results are in line with the effects of $\mathrm{T}_{3}$ on systolic and diastolic blood pressure. In fact, $\mathrm{T}_{3}$ is well known to increase the effect of catecholamines on cardiac output, stroke volume, heart rate, and cardiac contractility [23]. Moreover, Napoli et al. have shown that $\mathrm{T}_{3}$ directly enhances endothelium-dependent vasodilation on resistance vessels [24]. In addition, thyroid hormones have been shown to have direct vasodilatory effects on vascular muscle cells [25], 
TABLE 2: Pearson correlation coefficients of 24-h mean systolic (SBP) and 24-h mean diastolic blood pressure (DBP) with general, anthropometric, metabolic variables in subjects under study $(n=231)$.

\begin{tabular}{lcc}
\hline & $\mathrm{SBP}(\mathrm{mmHg})$ & $\mathrm{DBP}(\mathrm{mmHg})$ \\
\hline Age $(\mathrm{yrs})$ & 0.116 & $0.214^{* * *}$ \\
Body mass index $\left(\mathrm{kg} \cdot \mathrm{m}^{-2}\right)$ & 0.110 & $-0.161^{*}$ \\
Waist circumference $(\mathrm{cm})$ & $0.180^{* *}$ & -0.097 \\
Fasting blood glucose $(\mathrm{mg} / \mathrm{dL})$ & 0.005 & -0.002 \\
Fasting insulin $(\mu \mathrm{UI} / \mathrm{mL})$ & 0.081 & -0.02 \\
HOMA $_{\text {IR }}$ & 0.069 & -0.025 \\
Triglycerides $(\mathrm{mg} / \mathrm{mL})$ & 0.090 & 0.053 \\
HDL cholesterol $(\mathrm{mg} / \mathrm{mL})$ & 0.004 & 0.003 \\
Total cholesterol $(\mathrm{mg} / \mathrm{mL})$ & 0.058 & 0.076 \\
TSH $(\mu \mathrm{UI} / \mathrm{mL})$ & -0.068 & -0.108 \\
$\mathrm{FT}_{3}(\mathrm{pg} / \mathrm{mL})$ & $0.158^{*}$ & 0.019 \\
$\mathrm{FT}_{4}(\mathrm{pg} / \mathrm{mL})$ & 0.107 & 0.128 \\
\hline
\end{tabular}

${ }^{*} P<0.05,{ }^{* *} P<0.01,{ }^{* * *} P<0.001$.

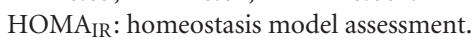

TABLE 3: Determinants of 24-h systolic blood pressure (SBP) in the multiple linear regression model.

\begin{tabular}{lcc}
\hline Variable & \multicolumn{3}{c}{$\mathrm{SBP}(\mathrm{mmHg})$} & \\
& $\beta$ & $P$ value \\
\hline $\mathrm{FT}_{3}(\mathrm{pg} / \mathrm{mL})$ & 0.163 & 0.015 \\
Male sex & 0.142 & 0.034 \\
Age $(\mathrm{yrs})$ & 0.179 & 0.008 \\
\hline
\end{tabular}

TABLE 4: Determinants of $24 \mathrm{~h}$ systolic blood pressure (SBP) in the multiple linear regression model.

\begin{tabular}{lcc}
\hline \multirow{2}{*}{ Variable } & \multicolumn{2}{c}{ SBP $(\mathrm{mmHg})$} \\
& $\beta$ & $P$-value \\
\hline $\mathrm{FT}_{3}(\mathrm{pg} / \mathrm{mL})$ & 0.126 & $\mathrm{~ns}$ \\
Male sex & 0.120 & $\mathrm{~ns}$ \\
Age $(\mathrm{yrs})$ & 0.195 & 0.003 \\
Waist circumference $(\mathrm{cm})$ & 0.152 & 0.026 \\
\hline
\end{tabular}

endothelial dysfunction may be more prevalent in hypothyroid patients [26,27], and increased diastolic blood pressure and higher arterial stiffening are present in subclinical hypothyroid patients [28].

Since $\mathrm{FT}_{3}$ serum levels have been shown to be higher in obese women with higher waist circumference [17], the effects of higher $\mathrm{FT}_{3}$ concentrations on the heart and on resistance vessels may contribute to the relationship between waist circumference and pulse pressure in our overweight and obese patients.

It is to note that the positive association between $\mathrm{FT}_{3}$ levels and daily mean SBP was not maintained when data were adjusted for waist circumference in multiple regression analysis, suggesting that the increase of $\mathrm{FT}_{3}$ levels and the possible influence of higher $\mathrm{FT}_{3}$ levels on systolic in obese subjects are just secondary to central fat accumulation.
TABLE 5: Pearson correlation coefficients of $24 \mathrm{~h}$ mean pulse pressure (PP) with general, anthropometric, metabolic, and hormone variables in overweight and obese subjects under study $(n=231)$.

\begin{tabular}{lc}
\hline & Pulse pressure $(\mathrm{mmHg})$ \\
\hline Age $(\mathrm{yrs})$ & 0.051 \\
Body mass index $\left(\mathrm{kg} \cdot \mathrm{m}^{-2}\right)$ & $0.332^{* * *}$ \\
Waist circumference $(\mathrm{cm})$ & $0.370^{* * *}$ \\
Fasting blood glucose $(\mathrm{mg} / \mathrm{dL})$ & -0.005 \\
Fasting insulin $(\mu \mathrm{UI} / \mathrm{mL})$ & $0.148^{*}$ \\
HOMA $_{\mathrm{IR}}$ & $0.152^{*}$ \\
Triglycerides $(\mathrm{mg} / \mathrm{mL})$ & 0.078 \\
HDL cholesterol $(\mathrm{mg} / \mathrm{mL})$ & 0.003 \\
Total cholesterol $(\mathrm{mg} / \mathrm{mL})$ & 0.007 \\
$\mathrm{TSH}(\mu \mathrm{UI} / \mathrm{mL})$ & 0.011 \\
$\mathrm{FT}_{3}(\mathrm{pg} / \mathrm{mL})$ & $0.215^{* * *}$ \\
$\mathrm{FT}_{4}(\mathrm{pg} / \mathrm{mL})$ & 0.025 \\
\hline
\end{tabular}

${ }^{*} P<0.05,{ }^{* *} P<0.01,{ }^{* * *} P<0.001$.

TABLE 6: Determinants of $24 \mathrm{~h}$ pulse pressure (PP) in the multiple linear regression model.

\begin{tabular}{lcc}
\hline Variable & \multicolumn{2}{c}{$\mathrm{PP}(\mathrm{mmHg})$} \\
& $\beta$ & $P$ value \\
\hline $\mathrm{FT}_{3}(\mathrm{pg} / \mathrm{mL})$ & 0.136 & 0.040 \\
Male sex & 0.059 & $\mathrm{~ns}$ \\
Age $(\mathrm{yrs})$ & 0.024 & $\mathrm{~ns}$ \\
Fasting insulin $(\mu \mathrm{UI} / \mathrm{mL})$ & -0.066 & $\mathrm{~ns}$ \\
Waist circumference $(\mathrm{cm})$ & 0.380 & $<0.001$ \\
\hline
\end{tabular}

In conclusion, the present study, performed in overweight and obese subjects, either normotensive or with recently discovered hypertension, shows that $\mathrm{FT}_{3}$ circulating levels are positively associated with pulse pressure, independently of age, sex, insulin levels, and insulin resistance. 
These results support the hypothesis that higher $\mathrm{FT}_{3}$ circulating levels per se may be responsible for an increase in systolic blood pressure and a decrease of diastolic blood pressure in subjects with abdominal obesity.

\section{References}

[1] C. D. Brown, M. Higgins, K. A. Donato et al., "Body mass index and the prevalence of hypertension and dyslipidemia," Obesity Research, vol. 8, no. 9, pp. 605-619, 2000.

[2] W. B. Drøyvold, K. Midthjell, T. I. L. Nilsen, and J. Holmen, "Change in body mass index and its impact on blood pressure: a prospective population study," International Journal of Obesity, vol. 29, no. 6, pp. 650-655, 2005.

[3] L. Niskanen, D. E. Laaksonen, K. Nyyssönen et al., "Inflammation, abdominal obesity, and smoking as predictors of hypertension," Hypertension, vol. 44, no. 6, pp. 859-865, 2004.

[4] J. E. Neter, B. E. Stam, F. J. Kok, D. E. Grobbee, and J. M. Geleijnse, "Influence of weight reduction on blood pressure: a meta-analysis of randomized controlled trials," Hypertension, vol. 42, no. 5, pp. 878-884, 2003.

[5] A. Must, J. Spadano, E. H. Coakley, A. E. Field, G. Colditz, and W. H. Dietz, "The disease burden associated with overweight and obesity," Journal of the American Medical Association, vol. 282, no. 16, pp. 1523-1529, 1999.

[6] R. J. Garrison, W. B. Kannel, J. Stokes, and W. P. Castelli, "Incidence and precursors of hypertension in young adults: the Framingham offspring study," Preventive Medicine, vol. 16, no. 2, pp. 235-251, 1987.

[7] V. Kotsis, S. Stabouli, M. Bouldin, A. Low, S. Toumanidis, and N. Zakopoulos, "Impact of obesity on 24-hour ambulatory blood pressure and hypertension," Hypertension, vol. 45, no. 4, pp. 602-607, 2005.

[8] T. Hayashi, E. J. Boyko, D. L. Leonetti et al., "Visceral adiposity is an independent predictor of incident hypertension in Japanese Americans," Annals of Internal Medicine, vol. 140, no. 12, pp. 992-1000, 2004.

[9] L. Landsberg, "Insulin resistance and the metabolic syndrome," Diabetologia, vol. 48, no. 7, pp. 1244-1246, 2005.

[10] G. Grassi, R. Dell'Oro, A. Facchini, F. Q. Trevano, G. B. Bolla, and G. Mancia, "Effect of central and peripheral body fat distribution on sympathetic and baroreflex function in obese normotensives," Journal of Hypertension, vol. 22, no. 12, pp. 2363-2369, 2004.

[11] G. E. Alvarez, S. D. Beske, T. P. Ballard, and K. P. Davy, "Sympathetic neural activation in visceral obesity," Circulation, vol. 106, no. 20, pp. 2533-2536, 2002.

[12] M. Hausberg, A. L. Mark, R. P. Hoffman, C. A. Sinkey, and E. A. Anderson, "Dissociation of sympathoexcitatory and vasodilator actions of modestly elevated plasma insulin levels," Journal of Hypertension, vol. 13, no. 9, pp. 1015-1021, 1995.

[13] T. L. Goodfriend, D. E. Kelley, B. H. Goodpaster, and S. J. Winters, "Visceral obesity and insulin resistance are associated with plasma aldosterone levels in women," Obesity Research, vol. 7, no. 4, pp. 355-362, 1999.

[14] R. Bentley-Lewis, G. K. Adler, T. Perlstein et al., "Body mass index predicts aldosterone production in normotensive adults on a high-salt diet," Journal of Clinical Endocrinology and Metabolism, vol. 92, no. 11, pp. 4472-4475, 2007.

[15] G. P. Rossi, A. Belfiore, G. Bernini et al., "Body mass index predicts plasma aldosterone concentrations in overweightobese primary hypertensive patients," Journal of Clinical Endocrinology and Metabolism, vol. 93, no. 7, pp. 2566-2571, 2008.
[16] G. Livshits, I. Pantsulaia, and L. M. Gerber, "Association of leptin levels with obesity and blood pressure: possible common genetic variation," International Journal of Obesity, vol. 29, no. 1, pp. 85-92, 2005.

[17] G. De Pergola, A. Ciampolillo, S. Paolotti, P. Trerotoli, and R. Giorgino, "Free triiodothyronine and thyroid stimulating hormone are directly associated with waist circumference, independently of insulin resistance, metabolic parameters and blood pressure in overweight and obese women," Clinical Endocrinology, vol. 67, no. 2, pp. 265-269, 2007.

[18] G. De Pergola, A. Nardecchia, P. Guida, and F. Silvestris, "Arterial hypertension in obesity: relationships with hormone and anthropometric parameters," European Journal of Cardiovascular Prevention and Rehabilitation, vol. 18, no. 2, pp. 240247, 2011.

[19] S. Kalra, B. Kalra, and N. Agrawal, "Combination therapy in hypertension: an update," Diabetology and Metabolic Syndrome, vol. 2, no. 1, article no. 44, 2010.

[20] G. Mancia, G. De Backer, A. Dominiczak et al., "2007 ESHESC practice guidelines for the management of arterial hypertension: ESH-ESC task force on the management of arterial hypertension," Journal of Hypertension, vol. 25, no. 9, pp. 1751-1762, 2007.

[21] G. De Pergola, F. Giorgino, R. Benigno, P. Guida, and R. Giorgino, "Independent influence of insulin, catecholamines, and thyroid hormones on metabolic syndrome," Obesity, vol. 16, no. 11, pp. 2405-2411, 2008.

[22] E. Bonora, G. Targher, M. Alberiche et al., "Homeostasis model assessment closely mirrors the glucose clamp technique in the assessment of insulin sensitivity: studies in subjects with various degrees of glucose tolerance and insulin sensitivity," Diabetes Care, vol. 23, no. 1, pp. 57-63, 2000.

[23] G. S. Levey and I. Klein, "Catecholamine-thyroid hormone interactions and the cardiovascular manifestations of hyperthyroidism," American Journal of Medicine, vol. 88, no. 6, pp. 642-646, 1990.

[24] R. Napoli, V. Guardasole, V. Angelini et al., "Acute effects of triiodothyronine on endothelial function in human subjects," Journal of Clinical Endocrinology and Metabolism, vol. 92, no. 1, pp. 250-254, 2007.

[25] I. Klein and K. Ojamaa, "Thyroid hormone: targeting the vascular smooth muscle cell," Circulation Research, vol. 88, no. 3, pp. 260-261, 2001.

[26] J. Lekakis, C. Papamichael, M. Alevizaki et al., "Flowmediated, endothelium-dependent vasodilatation is impaired in subjects with hypothyroidism, borderline hypothyroidism, and high-normal serum thyrotropin (tsh) values," Thyroid, vol. 7, no. 3, pp. 411-414, 1997.

[27] S. Taddei, N. Caraccio, A. Virdis et al., "Impaired endothelium-dependent vasodilatation in subclinical hypothyroidism: beneficial effect of levothyroxine therapy," Journal of Clinical Endocrinology and Metabolism, vol. 88, no. 8, pp. 3731-3737, 2003.

[28] T. Nagasaki, M. Inaba, Y. Kumeda et al., "Increased pulse wave velocity in subclinical hypothyroidism," Journal of Clinical Endocrinology and Metabolism, vol. 91, no. 1, pp. 154-158, 2006. 


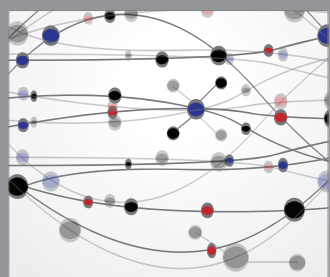

The Scientific World Journal
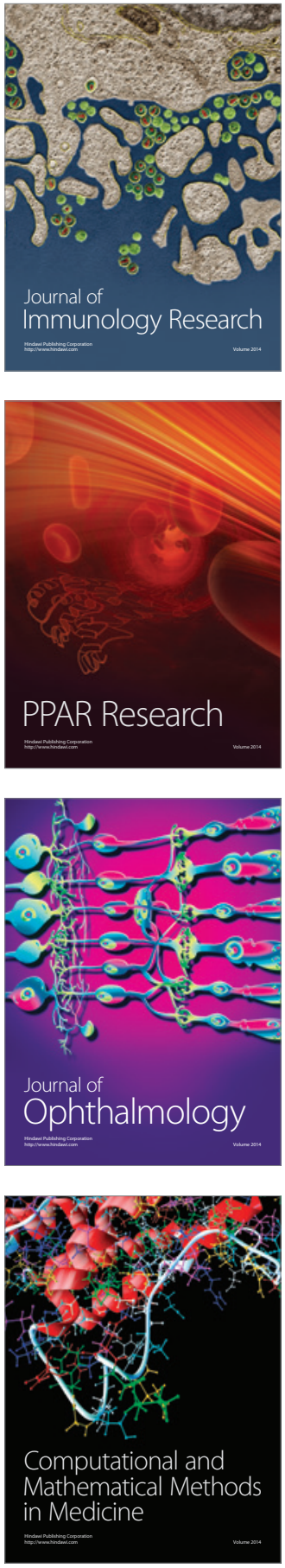

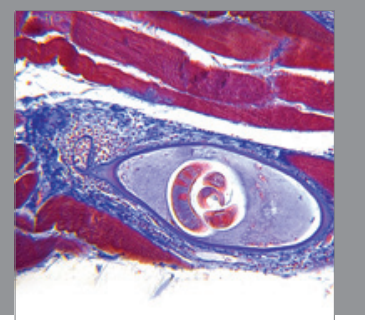

Gastroenterology

Research and Practice
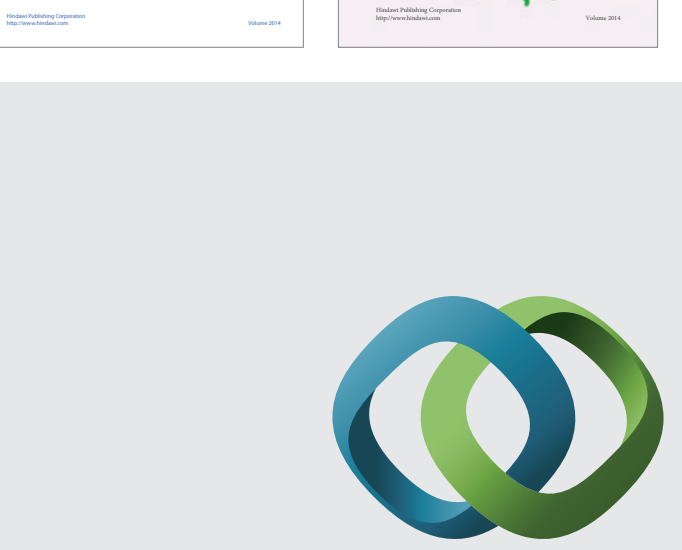

\section{Hindawi}

Submit your manuscripts at

http://www.hindawi.com
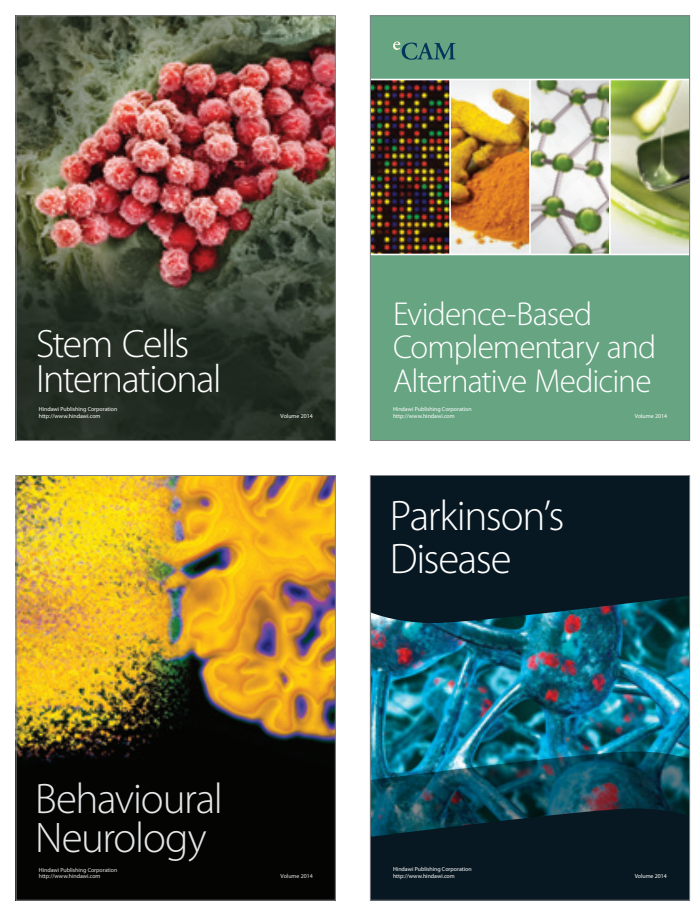

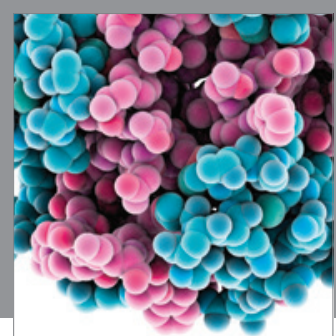

Journal of
Diabetes Research

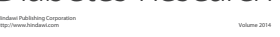

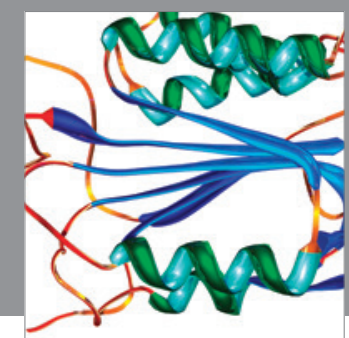

Disease Markers
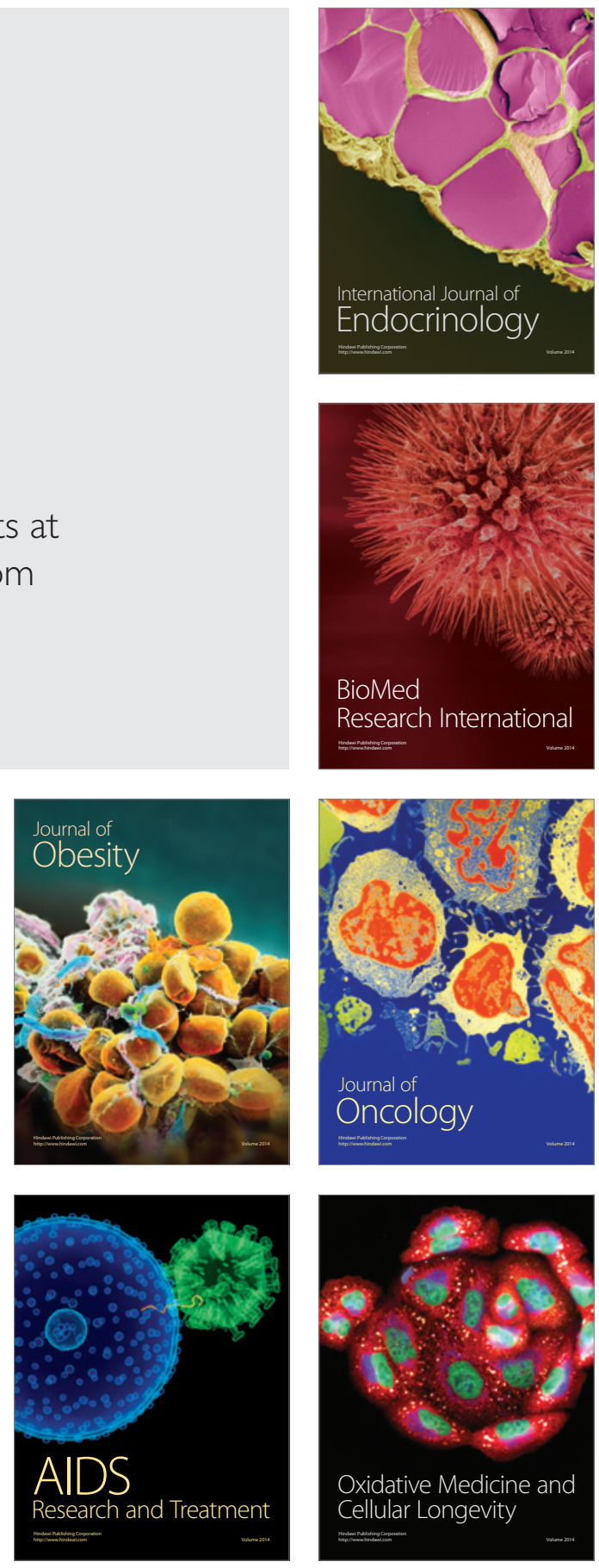